\title{
Remediation of Dysfunctional Families
}

\section{K. Minarovicova (Katarina Minarovicova)}

Constantine the Philosopher University in Nitra, SK

\section{Original Article}

\section{E-mail address:}

kminarovicova@ukf.sk

\section{Reprint address:}

Katarina Minarovicova

Faculty of Social Sciences and Health Care

Constantine the Philosopher University in Nitra

Kraskova 1

94974 Nitra

SK

Source: Clinical Social Work and Health Intervention

Pages: $70-74$

Volume: 9

Issue: 2

\section{Reviewers:}

Steve Szydlowski

University of Scranton School of education, USA

Victor Namulanda Wanjala

Catholic university of Eastern Africa, Nairobi, KE

\section{Key words:}

Dysfunctional family. Parenting skills. Remediation. Accompaniment.

\section{Publisher:}

International Society of Applied Preventive Medicine i-gap

CSWHI 2018; 9(2): 70 - 74; DOI 10.22359/cswhi_9_2_10 @ 2018 Clinical Social Work and Health Intervention

\section{Abstract:}

Objective: This article presents the results of Social Work with dysfunctional families of children in foster homes; with families threatened by the exclusion of children from the family environment; with families of adolescents and young adults who had returned from institutional care. It stresses the importance of Social Work in the natural family environment of clients, encouraging parents to change their behavior towards their children and the role of Social Workers in promoting positive changes in dysfunctional families. 
Participants: The research sample consisted of 100 families, which were divided into 3 groups:

1) Families with children placed in foster homes, crisis centers and reeducation centers - 63 families;

2) Families with imposed educational measures and threatened by the exclusion of a child - 23 families;

3) Families of adolescents and young adults who had returned from foster homes, reeducation, resocialization and crisis centers and pretrial detention centers or facilities for the execution of punishment - 14 families.

Methods: Content analysis of the collection of documents of selected families and author's own observation. The clients' collections of documents consisted of the following:

- an anamnesis report on the family (provided by the promoters of the social project and supplemented by further data on the client collected by Social Workers from relevant authorities and institutions;

- social diagnostics of the family prepared according to the methodology of the program PRIDE by which we identified the status of the family in terms of its strengths and weaknesses, ecomaps, genocharts, developmental puzzle of the child;

- a table with the history of losses of each family member and the socalled "analysis of the causes of the crisis".

Results: The main objective of the research was to find out which factors positively influenced the process of remediation and its results. After evaluating the results of our research, we can conclude that these were the changes that the parents were willing and able to make so that their children could be returned to the families or the children could remain living in biological families). Another factor that influenced the results of working with the family was the time of cooperation with the family for the purpose of its remediation.

Conclusion: The results which are presented are the results of teamwork of Social Workers of the accredited body Society of the Friends of Children from Children's homes Smile As A Gift in Nitra in cooperation with other entities involved in social projects that were under my professional supervision. In the case of 57 families I worked as a field Social Worker, too.

\section{Introduction}

Taking care of children living in foster homes is a topic that is often discussed by the specialist public. Taking into account all the aspects of care of children living outside their own biological family requires not only expertise, but also warm hearts of people working with these children who must be responsive to their needs. Children who must live separated from their families are experiencing relational anxiety and uncertainty (Bowlby 2012). Similarly Hasto (2005, p. 90) reported that "for healthy child development is a 'safe bond' in which the child knows that stress and anxiety inducing 
situations can rely on parental emotions and active support".

In the research are analyzed the results of Social Work with dysfunctional families. My workload was to coordinate these social projects and carry out field Social Work in selected families (Minarovicova, K 2015). Our intention was to make families become places in which children can find understanding, love and acceptance as Satirova states (1994).

\section{Research Objectives}

The main objective of the research was to find out which factors positively influenced the process of remediation and its results. Along with specifying the main objective we have set the following intermediate objectives to:

1) determine whether the time of separation of the child from its family affects the parents ${ }^{6}$ interest in the child as well as their efforts to change the family circumstances.

2) determine what changes the family has made in order to solve their situation.

3) find out what time of cooperation with the family is optimal for achieving and consolidating changes in its functioning.

\section{Research Methods}

The research methods that we have chosen to process the results of our research were content analysis of the collection of documents of selected families and our own observation. Important materials that were part of the family's collections of documents included the plan of Social Work with the child and his family; a sheet with records on working with the family; which included the aim of meeting with the family; its course; place of realization; names of attendees and the conclusions of the meeting; or tasks that had been agreed on by the family and Social
Workers. The collection of documents included also records of Social Workers on meetings with other members of the training team; records from coordination meetings; copies of previous court decisions related to family members; reports on the child prepared by the foster home; etc.

We carried out our own observation during the performance of field Social Work in families as well as during the coordination of my colleagues' work whom I accompanied in the process of Social Work with the families.

\section{Research Results}

In this paper we present selected results of our research regarding the intermediate objectives that have been defined above. Data relating to the evaluation of the intermediate objective No.1:

"To determine whether the time of separation of the child from the family affects the parents' interest in the child as well as their efforts to improve the family's circumstances", are:

\subsection{Time of separation of the children from their biological families}

In the case of 63 families of separated children there were 41 children who had been separated from their families for a period of less than 6 months to 2 years. The remaining 71 children had been separated from their families for 3 or more years. The number of children exempted from biological families were total 112 children.

\section{Time of separation of adolescents and young adults from their families}

When determining the period of separation of 14 adolescents and young adults we found that for 8 adolescents and young adults the time of separation from the family was 2-5 years; 6 adolescents and young 
adults had a very long time of separation in the range of 9-18 years Including one young adult who had been in the foster home since his birth.

This phenomenon together with the reason for the exclusion hindered their integration into normal life as well as the possibility to be returned to their family.

\subsection{Changes biological families were willing and able to make in order to solve their situation}

Data related to the evaluation of the objective No. 2:

"To find what changes the families had made in order to solve their situation" are as follows:

In 26 families of excluded children the relationship between the children and parents improved to such an extent that it was possible to return the children to their families by abolishing the court decision for institutional care or cancelling the preliminary measure under which the child had been placed in the facility enforcing.

\section{Changes the families with imposed educational measures were willing} and able to make in order to solve their situation

Of the total 23 families with imposed educational measures, in 17 families we noticed positive changes in the relationship between parents and children during our interaction. In families the level of hygiene habits of children and the ability of parents to maintain the standard of hygiene in their home have improved significantly.

\subsection{Time of cooperation with}

\section{dysfunctional families}

Data relating to evaluation of the objective No. 3:
"To find out what time of cooperation with the family was optimal for achieving and consolidating the changes in the family's functioning”, are as follows:

\section{Time of our cooperation with families whose children had been excluded from \\ their care}

Of the 63 families we carried out intensive field Social Work with 48 families for 1 year. We worked repeatedly with 15 other families, i.e. for the next 2 years, when the families were again included in the remediation project.

\section{Time of our cooperation with families} with imposed educational measures and families threatened by the exclusion of a child

In 23 families with imposed educational measures we worked intensively with 13 of them for 9 months during the project. We worked with 7 families in the framework of projects that were set for the duration of 1.5 years from the beginning of their implementation.

\section{Time of our cooperation with the families of adolescents and young adults}

The positive examples were the stories of 12 young adults whose found work and housing themselves, although in a different city, and managed to reintegrate fully into social life.

We accompanied 2 young adults for a period of 9 months during which we tried to consolidate their relationships with their mothers after they returned from a re-education center.

\section{Conclusion}

The main objective of the research was to find out which factors positively influenced 
the process of remediation and its results. After evaluating the results of our research, we can conclude that these were the changes that the parents were willing and able to make so that their child/children could be returned to the families or the child/children could remain living in biological families. Another factor that influenced the results of working with the family was the time of cooperation with the family for the purpose of its remediation. As stated by Fero, M., Miklosko, J., Mikloskova, M. (2016, p. 146),

"family contacts can be the factor affecting the child's behavior, whether keeping the continuity of original child's relationships relates to the more balanced, less problematic child's behavior in the children's home."

During our projects we worked intensively with the families on adjusting their socioeconomic conditions; restoring the broken relationship between family members; strengthening parenting skills in relation to the child. Another important factor that has a positive effect in the process of family remediation was the action of a multidisciplinary team. Gazikova states (2014, p. 53):

„Mutual cooperation of a multidisciplinary team is an important prerequisite for effective assistance in working with a child from the children's home and his family."

We cooperated with workers of the institutions of social protection of children and social guardianship; with the staff of foster homes; crisis centers; re-education centers; local authorities; workers of primary and secondary schools; medical facilities; the Center of Pedagogical and Psychological Counseling and Prevention.

\section{References}

1. BOWLBY J (2012) Separation. Prague: Portal, 2012. 400 p. ISBN 978-80-2620076-5.

2. FERO M, MIKLOSKO J, MIKLOSKOVA M (2016) Problematic Behavior of Children in Institutional Care - a problem for the adults taking care of them. How can we eliminate behavioral problems of children separated from their families? In: Social Pathology Updates I. Warsaw: Warsaw Management University Publishing House. 2016. 135-155p. ISBN 978-83-7520-206-9.

3. GAZIKOVA E (2014) Risk behavior of children in children's homes. Nitra: UKF in Nitra. 136 p. ISBN 978-80-558-0686-0.

4. HASTO J (2005) The roots of love and anxiety. Trencin: Publishing F. 300 p. ISBN 808895228X.

5. MINAROVICOVA K (2015) Remediation of the family environment of children from dysfunctional families. Bratislava: Society for the Development of Social Work. 179 p. ISBN 978-80-971445-4-8.

6. SATIROVA V (1994) Book of family. Praha: Institute of Virgine Satirova 350 p. ISBN 978-80-90132-50-4. 